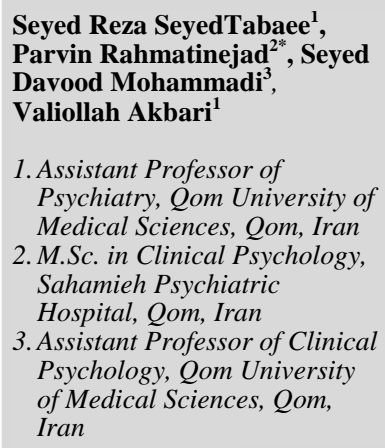

*Corresponding Author: M.Sc. in Clinical Psychology, Sahamieh Psychiatric Hospital, Qom, Iran

Tel: 025 - 37839933

E-mail: rahmatinejadp@yahoo.com

\section{Psychological Defense Mechanisms and Alexithymia in Cancer Patients}

Received:24 Apr. 2016 ; Accepted: 3 Apr. 2018

\section{Abstract}

Introduction: The goal of this research was to compare Alexithymia and psychological defense mechanisms in cancer patients with normal group. Also, investigation of the predictive role of three defense mechanisms in Alexithymia was considered.

Materials and Methods: From chemotherapy ward of Shahid Beheshti hospital of Qom city, 45 cancer patients were selected by convenient sampling method. Also, 45 employees of this hospital were included as the normal group. Defense Mechanisms Questionnaire and Toronto Alexithymia Scale-20 were used. Data was analyzed with Independent Sample T-test, Pearson Correlation and Multivariate Regression.

Results: Compared with normal people, cancerous patients had higher scores in alexithymia $(p=0.01)$, difficulty in emotions recognition subscale $(p=0.03)$ and nondeveloped defense mechanisms $(p=0.007)$. Non-developed defense mechanisms had significant relationships with alexithymia and difficulty in emotion's recognition and description subscales $(p<0.01)$, also non-developed defense mechanisms could predict alexithymia in cancerous patients $(p<0.005)$.

Conclusions: Findings indicates that cancer is a stressful event that can cause nondeveloped defense mechanisms start to emerge as dominant psychological defense mechanisms in the majority of patients. Alexithymia which has a relation with defense mechanisms is also a dynamic reaction for coping with unpleasant emotions driven by the illness.

Keywords: Psychological defense mechanisms, Alexithymia, Cancer 


\section{مكانيسمهاى روانى - دفاعى و آلكسى تايميا در بيمار ان مبتلا به سرطان}

تاريخ دريافت مقاله: 9Q/T/D؛ تاريخ بذيرش:9V/1/TY

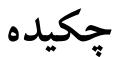

مقدمه: هدف از اين مطالعه مقايسه نوع مكانيسمهاى دفاعى مورد استفاده و آلكسىتايميا در بيماران مبتلا به سرطان با افراد

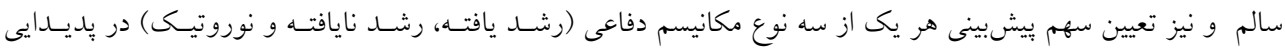
آلكسى تايميا بود. روش: از بين بيماران مبتلا به سرطان مراجعهكنتله به بخش شيمىدرمانى بيمارستان شهيد بهشـتى شـهر قـم ه广 بيمـار بـهـ صورت نمونه گيرى در دسترس انتخاب شدند. هष فرد سالم نيز به شيوه همتاسازى از بين كاركنان كادر يرستارى بيمارستان شهيد بهشتى وارد يزو هش شدند. دادهاى جمعآورى شده بوسيله يرسشنامهاى سبكهاى دفاعى و مقياس آلكسى تايمياى تورونتو با استفاده از آزمونهاى آمارى تى مستقل، همبستخى يِيرسون و رگرسيون جنـل متغيره مورد تجزيسه و تحليـل قـرار كر فتند. نتايج: در مقايسه با افراد سالم، بيماران مبتلا به سرطان، نمرات بـالاترى در مقيـاس آلكسسىتايميـا ( ( / P= P)، زيرمقيـاس

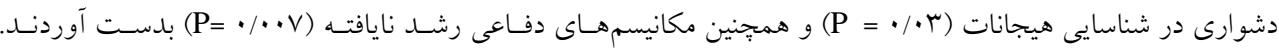
مكانيسمهاى دفاعى رشد نايافته با نمره كلى مقياس آلكسى تايميا و زيرمقياسهاى دشوارى در شناسايى هيجان و توصسيف هيجان همبستكى معنادار داشتند ( ( • • > P). مكانيسمهاى دفاعى رشد نايافته قادر به بيشبينى آلكسى تايميا در افراد مبتلا

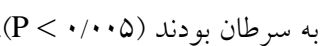
بحث: يافتههاى حاصل از اين ئزوهش حاكى از آن است كه ابتلا به سرطان به عنوان يكى رويداد اسـترسزا منجسر بـه راهاندازى مكانيسمهاى دفاعى رشد نايافته به عنوان مكانيسمهاى روانى غالب در اكثر بيمار ان مبتلا مىشود. آلكسى تايميـا كـه ارتباط تنخاتنكى با مكانيسمهاى دفاعى رشد نايافته دارد نيز يك واكنش ديناميك براى مقابله با هيجانات ناخوشايند ناشىى از رويداد بيمارى است.

كلمات كليدى: مكانيسمهاى روانى - دفاعى، آلكسىتايميا، سرطان

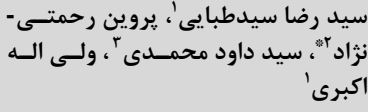

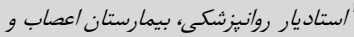

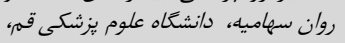

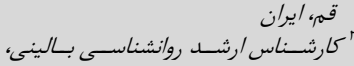
قبمارستان اعصاب و روان سـهاميه، قـمه، رواني، قمه، ايران

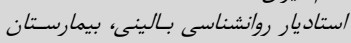

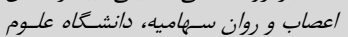
يزشكى قمه، /يران (1) 
نقص در آحَاهى هيجـانى، فقــان قــدرت تمـايز بـين هيجانـات و

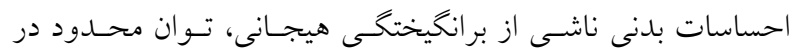
تخيل و فقر خياليردازى و سبك شناختى محدود به جهـان بيرونسى

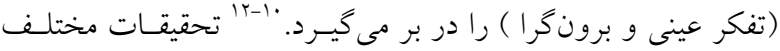

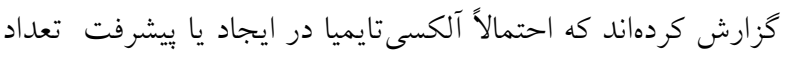

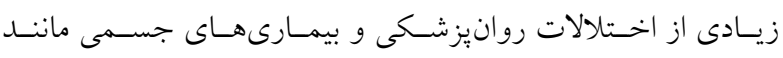

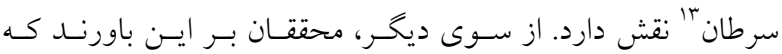
آلكسى تايميا در ايجـاد بِيبنـدى درمـانى Treatment compliance و

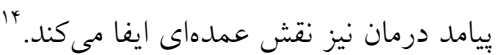
در بيماران مبتلا به سرطان، يزوهشهاى متعلدى صورت گرفته

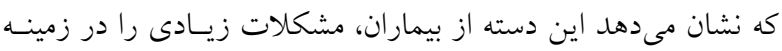
آكاهى و تنظيم هيجانى از جمله آلكسى تايميا تجربه مى كنــــ. نتـايج بدست آمده از اين مطالعات، به طـور كلـى حـاكى از آن اسـت كـه

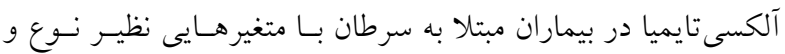

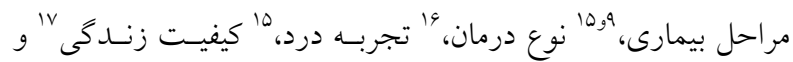

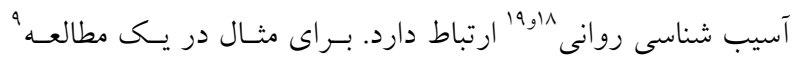

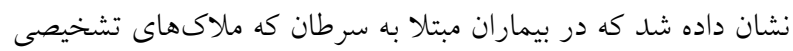
لازم براى اختلالات سايكوسوماتيك را دارند سطوح بالاى آلكسى-

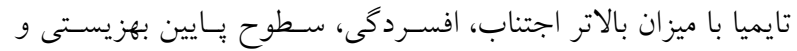

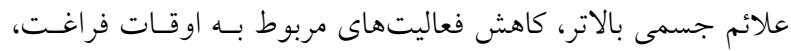

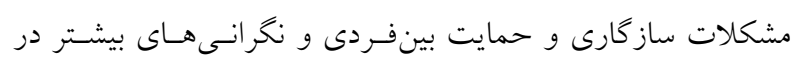

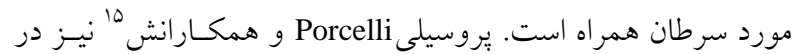
يكى يزوهش مقطعى به اين نتيجه رسيدند كـه آلكسى تايميـا بـويزه دشوارى در شناسايى هيجانـات ارتبـاط نزديكسى بـا تجربـه درد در بيماران مبتلا به سرطان دارد. در يك مطالعه ديخـر، نتـايج حساكى از

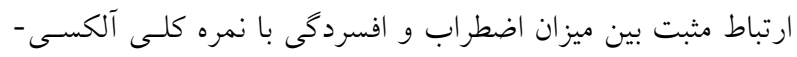

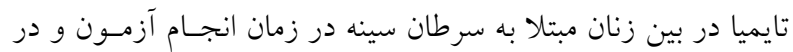

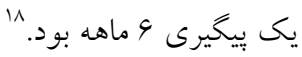

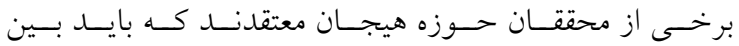
آلكسى تايمياى اوليـه كـه يـك ويز كـى شخصـيتى باثبـات اسـت و و آلكسى تايمياى ثانويه كه نوعى مكانيسم دفاعى و يكى واكنش خـذرا

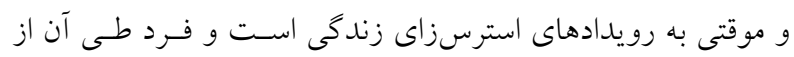

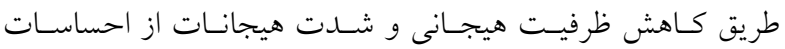

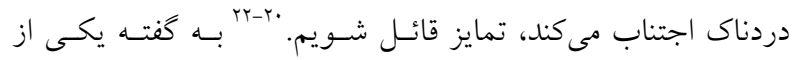

تشـخيص سـرطان و درمـانهـاى متعاقـب آن رويسـاد شــيدا

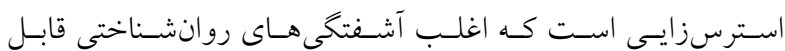
ملاحظهاى را براى فرد مبـتلا و اطرافيـان وى بـهـ همـــاه دارد. ايسن

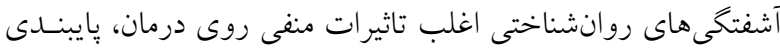

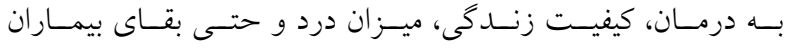

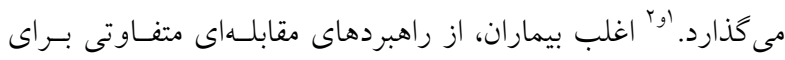
مديريت تجارب هيجانى روانشناختى و اجتماعى ناخوشايند ناشسى از تشخيص بيمارى استفاده مى كنند. قرارگرفتن در اين شرايط ماهيتاً استرسزا، مكانيسمهاى دفاعى -روانشناختى را در ايسن افـراد فعـال

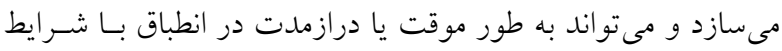
بيمارى موثر باشد. مكانيسمهاى دفاعى بنـا بـهـ تعريـف؛ فراينـدهاى

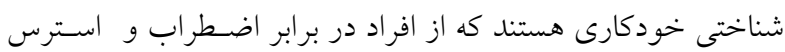

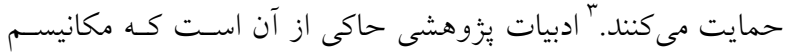
دفاعى انكار از شايعترين مكانيسـمهـاى دفــاعى مـورد اسـتفاده در

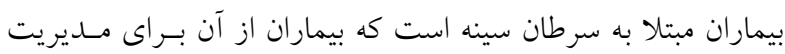

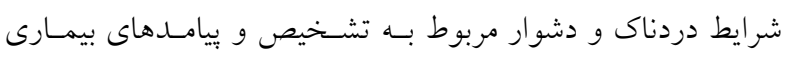

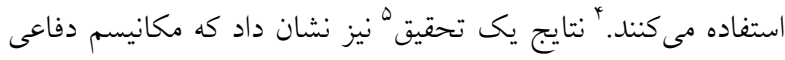

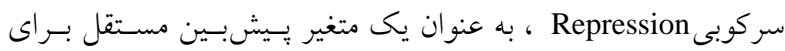
كيفيت زندكى مرتبط با سلامت جسمى در بيماران مبتلا به سـرطان كولوركتال عمل مى كند. ساير تحقيقات حاكى از آن است كه عمدهـترين مكانيسمهاى دفاعى شايع در بيماران مبتلا به سـرطان عبارتنـــ

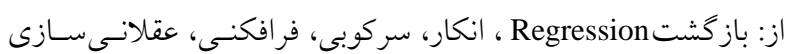

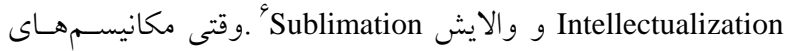
دفاعى كه در سه سطح رشد يافتـه، رشــ نايافتـه و نوروتيـك قـرار مى گيرند كارايى خود را در تنظيم هيجانات منفى از دست مى دهند

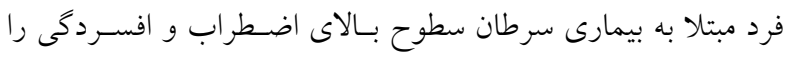

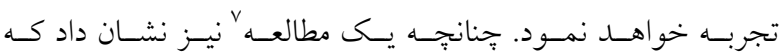
مكانيسمهاى دفاعى حتى مىتوانند شاخصى براى بقاى بيماران مبتلا به سرطان به حساب بيايند. يكى از ويزّكىهاى روانشناختى كه كفته مسىشـود در بيمـاران مبتلا به سرطان شيوع بالايى دارد آلكسى تايمياست. اهو آلكسى تايميـا Alexithymia اشاره دارد كه مشكلاتى در حوزه شناسايى و توصسيف احساسـات، 
آلكسى تايميا در بيماران مبتلا به سرطان ذكر كرد.

\section{مواد و روشها}

با توجه به ماهيت موضوع يزوهش مورد نظر از نوع همبستيكى

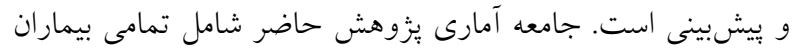

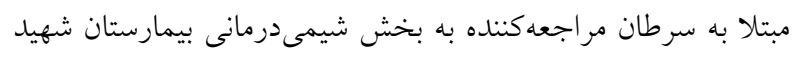

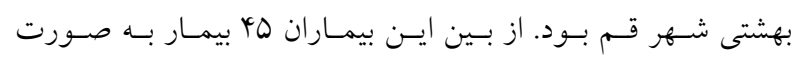

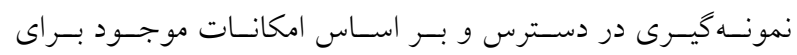

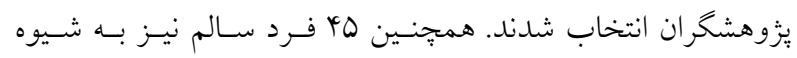

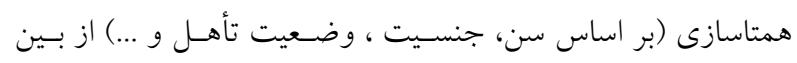

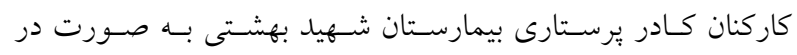

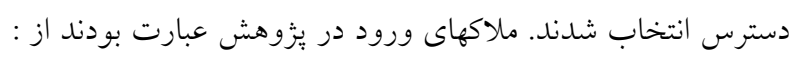

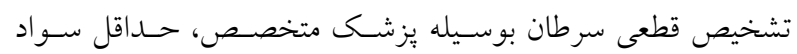

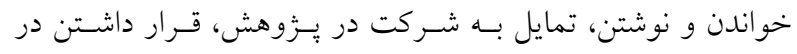

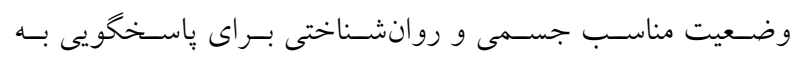

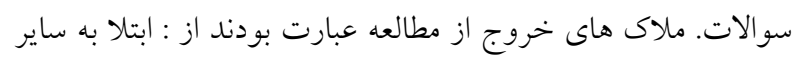

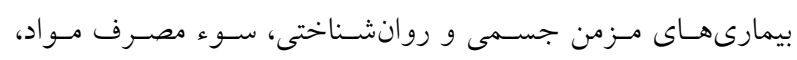

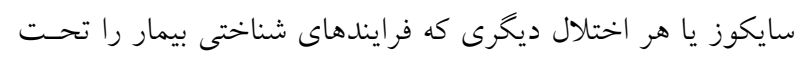

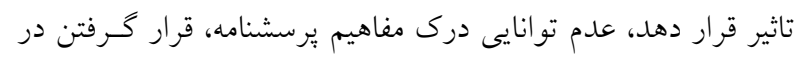
وضعيت حاد بيمارى، عدم برخو ردارى از هوشيارى كـافى. در ايـن فين يزوهش از ابزارهاى زير براى جمع آورى دادهها استفاده خرديد:

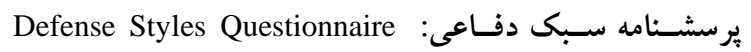

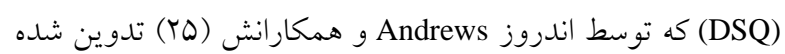

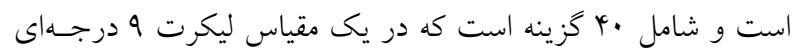

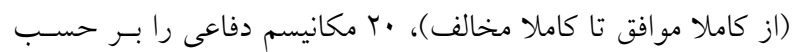

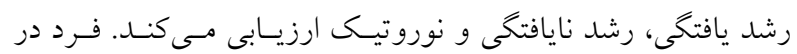

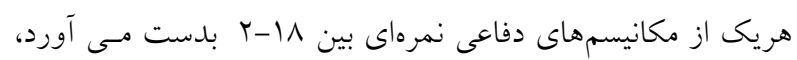

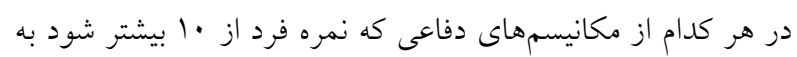

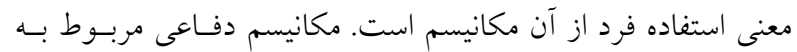

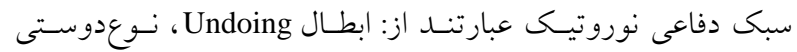

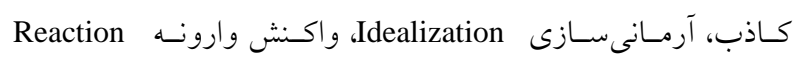
Formation

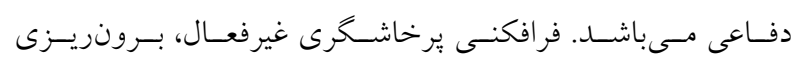

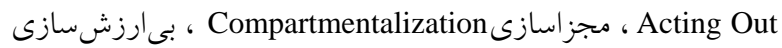

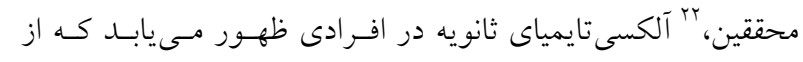

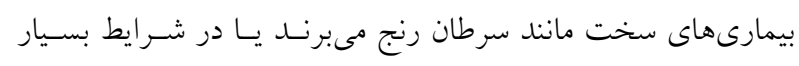
دشوار و اسـترسزاى عـاطفى و جسـمى از قبيـل هموديـاليز قـرار

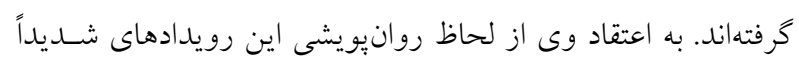

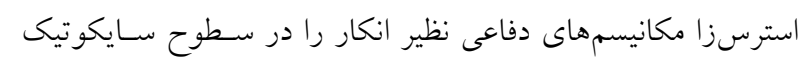

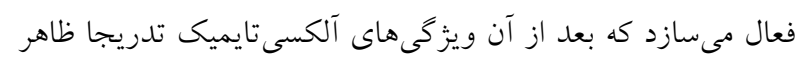

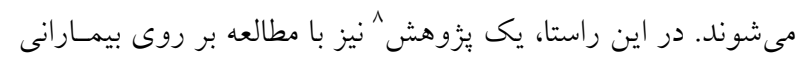

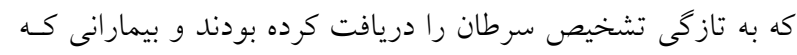

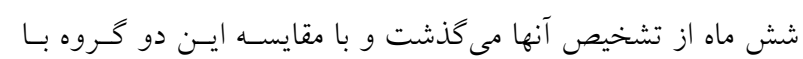

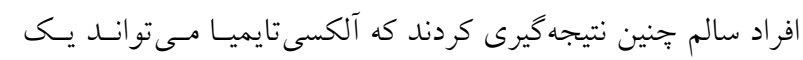

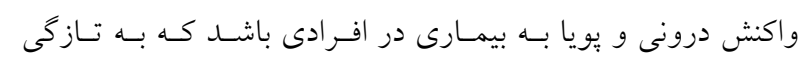

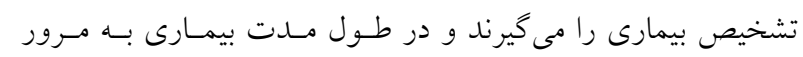

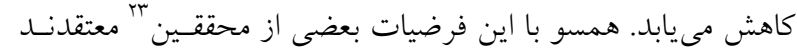

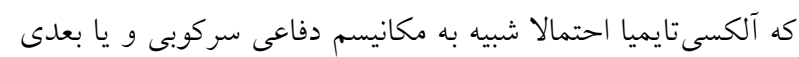

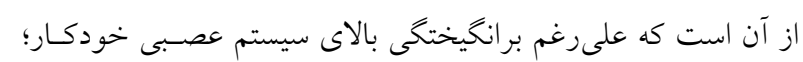
فرد آشفتكى هاى هيجانى كمى را تجربه مى كند.

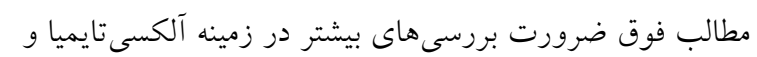

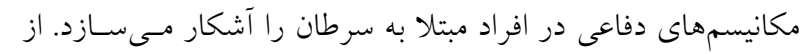
يك طرف، دادهها در مورد ميزان شيوع آلكسى تايميا در اين بيمـاران

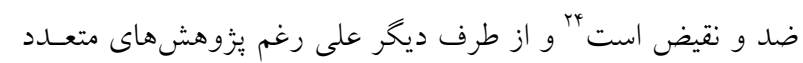

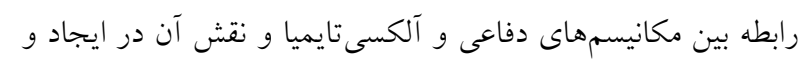

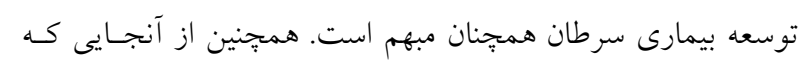

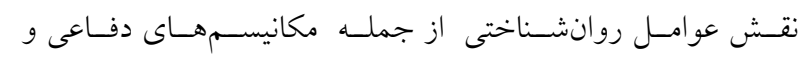

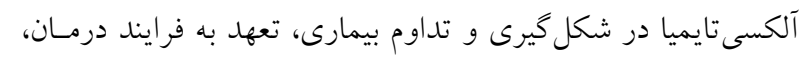

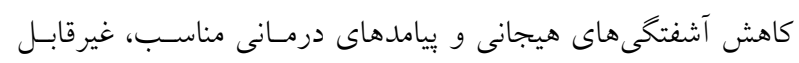

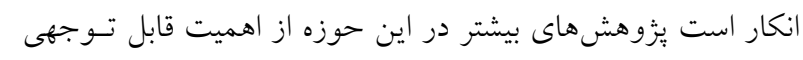

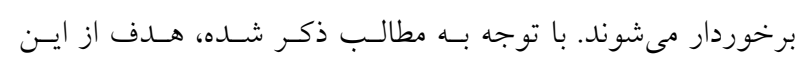

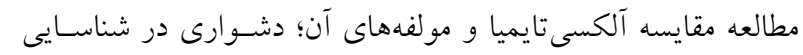

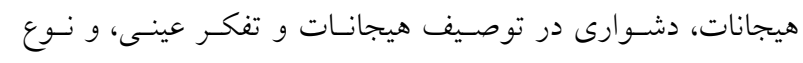

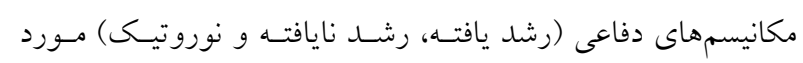

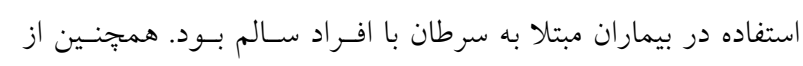

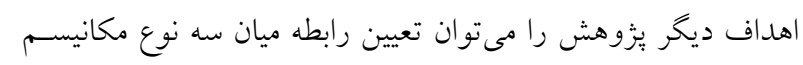

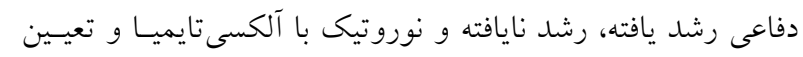

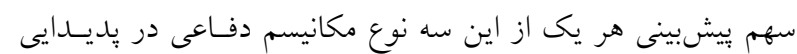


به صـورت در دسـترس انتخـاب شـدند تـا بـهـ سـوالات ايـن ســـ يرسشنامه بِاسخ دهند. براى كنترل اثر خستخى و ترتيب، مقيـاسهـا به تناسب با ترتيبهاى متفاوت ارائه گرديد. دادهها با استفاده از نرم افزار SPSS-23 مورد تجزيه و تحليـل قـرار كرفتــــ. بـراى تحليـل دادههاى بيزوهش از آمار توصيفى (ميـانخين، انحــراف معيـار و...) و

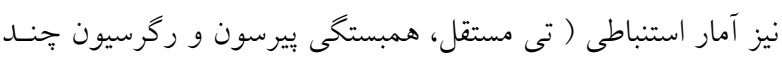
متغيره) استفاده شد.

\section{نتايج}

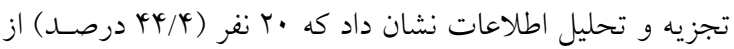

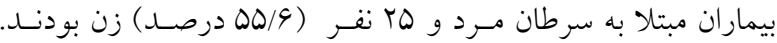

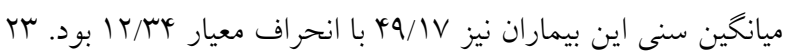

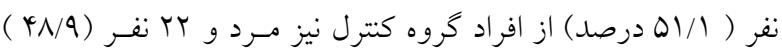

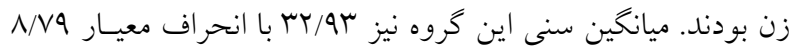

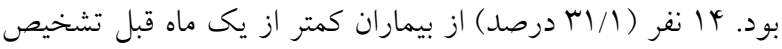
سرطان دريافت كرده بودند، 19 نفر (ه/4 درصد) بين شش مـاه تـا

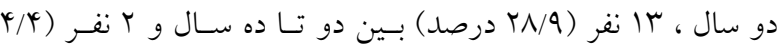
درصد ) نيز بيش از ده سال مبتلا به بيمارى سـرطان بودنـد. هـ نفـر

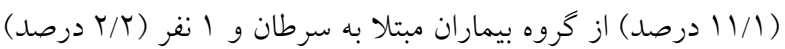
از افراد گروه كتترل سابقه بيمارى اعصـاب و روان داشـتند. با نقــر

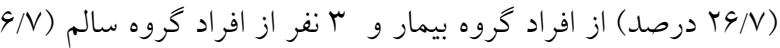
درصد) نيز سابقه مصرف سـيكار را ذكـر مسىكردنـد. V نفـر (ه/9 درصد) از بيماران مبتلا به سرطان نيز سابقه ابتلا به بيمارى سـرطان در بستخان درجه يك خود را كزارش دادند. بر اساس آزمون لوين و عدم معنادارى آن براى تمامى متغيرهاى يزوهش، شرط برابرى واريانسهـاى بـين گروهـى رعايـت شـــه ؛

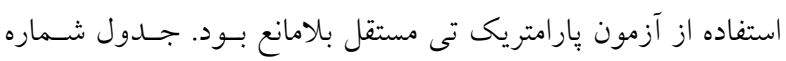

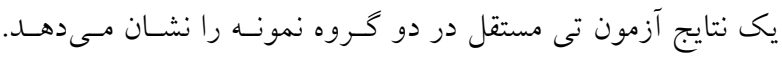
تجزيه و تحليل دادهها نشان داد كـه در سـطح معنـادارى هـ • • ، دو كروه نمونه در زيرمقيـاسهـاى شناسـايى هيجانـات [ ץ+/ = P P

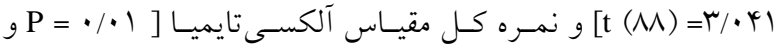

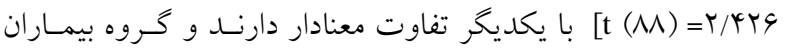
مبتلا به سرطان در هر دو متغير نمره ميانخين بالاترى نسبت به گروه

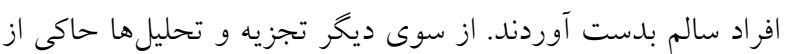

Devaluation

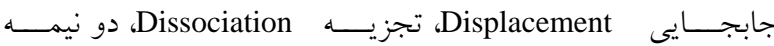
سازى Splitting، دليـلـراشـىRationalization و جسـمانى سـازى. مكانيسمهاى دفاعى رشــ يافتـه نيـز عبارتنـــ از: والايسش، شـوخـ طبعى Humor، يـيشبينى Anticipation، فرونشـانى Suppression. ضرايب آلفاى كرونباخ هريكى از مكانيسـمهــاى رشـــ يافتـه، رشـــ نايافته و نوروتيك در يك نمونه دانشجويى براى كل آزمودنىها بــه

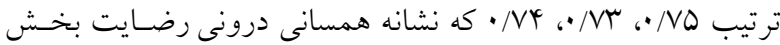
براى فرم ايرانى برسشنامه سـبكهــاى دفـاعى محسـوب مسى شـود.

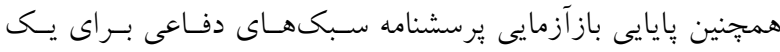

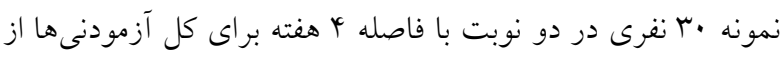
r

مقياس آلكسى تايمياى تورونتو - Toronto Alexithymia Scale 20 (TAS-20) دشوارى در شناسايى احساسات، دشـوارى در توصسيف احساسـات

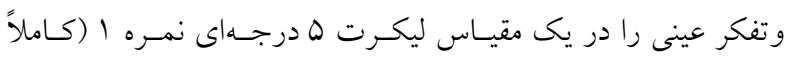
مخالف) تا نمره ه (كاملا موافق) ارزيابى مى كند. يكى نمره كل نيـز

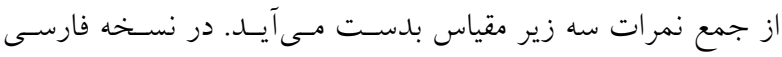
مقياس ناكويايى هيجانى تورنتو -·r ضرايب آلفاى كرونبـاخ بـراى نمره كل مقياس آلكسىتايميا و سه زير مقياس دشوارى در شناسايى احساسات، دشوارى در توصيف احساسات و تفكر عينى به ترتيـب

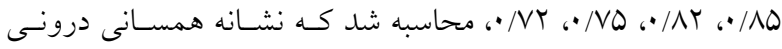
خوب مقياس است. يايايى بازآزمايى مقياس در يك نمونه VV نقرى

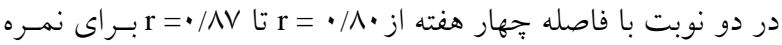
كل مقياس آلكسى تايميـا و زيــر مقيـاسهــاى مختلـف تاييــ شـــه iv.

شيوه اجراى يزوهش به صورت بود كه يس از كسب مجـوز از

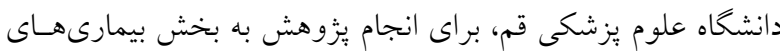
آنكولوزى و شيمى درمانى بيمارستان شهيد بهشتى مراجعه شـــ. بــه بيماران درباره هدف از انجـام يـزّوهش توضسيحات مختصـرى داده شده و يس از كسب رضايت بيمار براى شركت در اين پـرزوهش از

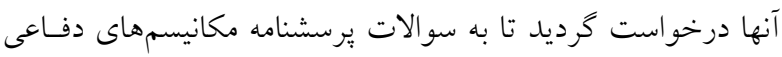
و مقياس آلكسى تايميا- تورنتو ياسخ دهند. براى نمونه گيرى گروه بره

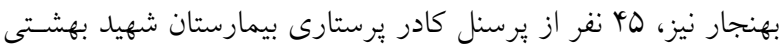


مكانيسم دفاعى رشد نايافته با نمره كلسى مقيـاس آلكسى تايميـا و

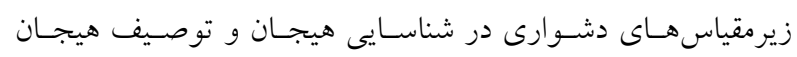

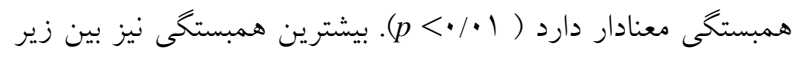

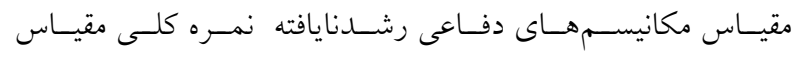

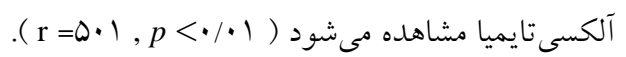

آن بود كه در سطح معنادارى ه•• • زيرمقيـاسهـاى مكانيسمهـاى دفاعى دو كروه تفاوت معنادارى در استفاده از مكانيسم دفاعى رشد درد

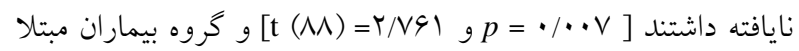
به سرطان نمرات ميانخين بالاترى نسبت به گروه افراد سالم بهدست آوردند. همانطور كه ماتريس همبستخى در جـدول r نشـان مسىدهـد،

\begin{tabular}{|c|c|c|c|c|c|c|c|c|c|}
\hline \multirow[t]{2}{*}{ df } & \multirow[t]{2}{*}{ sig } & \multirow[t]{2}{*}{$\mathbf{t}$} & \multirow{2}{*}{ تفاوت } & \multirow{2}{*}{ انحر افتاف اندارد } & \multirow[t]{2}{*}{ ميانخين } & \multicolumn{2}{|c|}{ آزمون لوين } & \multirow[t]{2}{*}{ كروه نمونه } & \multirow[t]{2}{*}{ متغيرها } \\
\hline & & & & & & sig & $\mathbf{f}$ & & \\
\hline \multirow[t]{2}{*}{ M } & $\cdot * r$ & $r / \cdot+\varphi l$ & T/GYT & $\Delta / \wedge)$ & $r \cdot / r \Delta$ & $\cdot / 4 \wedge \Delta$ &.$/ 491$ & كروه بيمار & دشوارى در شناسايى هيجانات \\
\hline & & & & $Q / \uparrow \wedge$ & $19 / \mathrm{Nr}$ & & & كروه سالم & \\
\hline \multirow[t]{2}{*}{$M$} & $\cdot / \Lambda \mu_{\Lambda}$ & $\cdot / \pi \cdot \Delta$ &.$/ \mathrm{VV}$ & $r / 9 V$ & $1 \% / 44$ & $\cdot / \Delta \Delta \Delta$ & $\cdot / \pi \Delta 1$ & كروه بيمار & دشوارى در توصيف هيجانات \\
\hline & & & & $r / T \mu$ & $1 r / T 4$ & & & كروه سالم & \\
\hline \multirow[t]{2}{*}{ м } & $\cdot / \cdot \wedge V$ & I/NTr & $1 / T \& V$ & $r / \mu r$ & $r \mid / 91$ & $\cdot / 91 \mathrm{r}$ & $\cdot \cdots$ & كروه بيمار & تفكر عينى \\
\hline & & & & $r / 4 q$ & $r \cdot / 94$ & & & كروه سالم & \\
\hline \multirow[t]{2}{*}{ м } &.$/ \cdot 1 \mathrm{~V}$ & T/KYG & $0 / \cdot 9 \mathrm{~V}$ & $9 / \Gamma \wedge$ & $\Delta \Delta / V I$ & $\cdot / 91 \mathrm{r}$ & $\cdot \cdots$ & كروه بيمار & نمره كل آلكسى تايميا \\
\hline & & & & $1 \cdot / 4 q$ & $0 \cdot / 94$ & & & كروه سالم & \\
\hline \multirow[t]{2}{*}{ M } &.$/ \cdot r$ & $r / r \cdot 9$ & $\Delta / \cdots$ & $11 / 49$ & $49 / 10$ & D & $1 / 40$ & كروه بيمار & مكانيسم دفاعى رشد يافته \\
\hline & & & & $\Lambda / 9$ & $41 / 10$ & & & كروه سالم & \\
\hline \multirow[t]{2}{*}{$\Lambda$} & $\cdot / \cdot V$ & T/VGI & $1 T / 99 \mathrm{~V}$ & $r \mu / Q \Lambda$ & $1 \cdot 1 / 49$ & 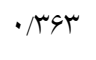 & $\cdot / A \mu_{c}$ & كروه بيمار & مكانيسم دفاعى رشد نايافته \\
\hline & & & & $19 / \mathrm{VV}$ & $9 \Delta / \wedge \cdots$ & & & كروه سالم & \\
\hline \multirow[t]{2}{*}{$\Lambda$} & $\cdot / 41 \wedge$ & $\cdot / A \mid Y$ & $r / \bullet \wedge 9$ & $|r /| F$ & $\varphi \Delta / \mu \Delta$ & $\cdot / 491$ & $\cdot / 4 V V$ & كروه بيمار & مكانيسم دفاعى نوروتيك \\
\hline & & & & $11 / 1 T$ & 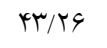 & & & كروه سالم & \\
\hline
\end{tabular}

جدول Y: ماتريس همبستخى ميان متغيرهاى بززوهش در گروه بيماران مبتلا به سرطان

\begin{tabular}{ccccccc}
\hline$V$ & $r$ & $r$ & 1 & 1 \\
\hline \\
\hline
\end{tabular}


جدول r: خلاصه ركرسيون جندمتغيره، تحليل واريانس و شاخصهاى آمارى رگرسيون آلكسى تايميا از روى مكانيسمهاى دفاعى رشد يافته، رشد

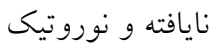

\begin{tabular}{|c|c|c|c|c|c|c|c|c|c|}
\hline خطاى بر آورد & $\mathbf{R}^{2}$ & $\mathbf{R}$ & $\mathbf{P}$ & $\mathbf{F}$ & ميانگين مجذورات & df & & مجموع مجذورات & مدل \\
\hline \multirow[t]{3}{*}{$V / 909$} & $\cdot / \mu \wedge$. & .1919 & $\cdot / \cdots$ & $\Lambda / r V \Lambda$ & $\mid 491 / 4 r q$ & $r$ & $\mid Y V Y / Y \wedge 9$ & ركرسيون & 1 \\
\hline & & & & & $\Delta N / 9 \Delta \Lambda$ & 41 & $Y \psi \cdot Y / q Q \Lambda$ & باقى مانده كلى & \\
\hline & & & & & & ky & rAVQ/TYY & & \\
\hline
\end{tabular}

جدول fا: ضريب همبستكى رگرسيون آلكسى تايميا از روى مكانيسمهاى دفاعى رشد يافته، رشد نايافته و نوروتيك

\begin{tabular}{|c|c|c|c|c|c|c|}
\hline سطح معنادارى & $T$ & ضريب بتا & خطاى استاندارد بر آورد & ضريب B & متغير & مدل \\
\hline 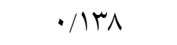 & $-1 / 010$ &.$- / 19 V$ & $V / \mu r$ &.$- / 191$ & رشد يافته & 1 \\
\hline$\cdot \cdots$ & $r / \mu r$ & . $/ 0$ M & .11 .9 & 饰 & رشد نايافته & \\
\hline .1 .91 & $-1 / A V Q$ & $-\cdot /$ TYQ & $.1 \% 4$ & $-\cdot / 1 V Q$ & نوروتيك & \\
\hline
\end{tabular}

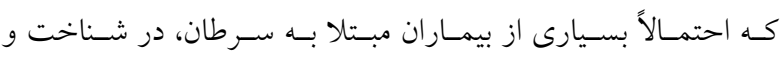
توصيف هيجانات خود ناتوان هستند. اين ناتوانى كه بويزه در زمينه

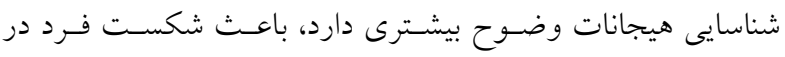
تنظيم هيجانـات منفـى مسىــود. بيمـارانى كـه قـادر بـه شناسـايى هيجانات منفى و تنظيم آن نيسـتند مشـكلات زيـادى را در زمينـه

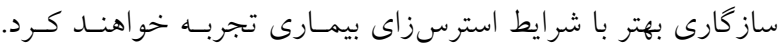

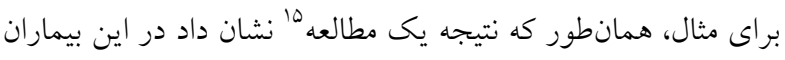
دشوارى در شناسايى و توصيف هيجان با متغيرهايى نظير رفتارهاى غيرانطباقى بيمارى و حساسيت بالا نسبت به تجربه درد و استفاده از راهبردهاى مقابلهاى ناسالم براى مــديريت هيجانـات منفى ارتبـاط

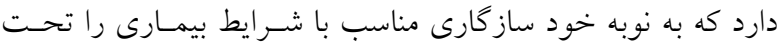

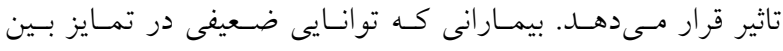

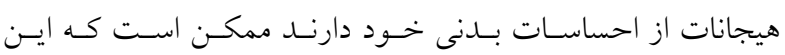

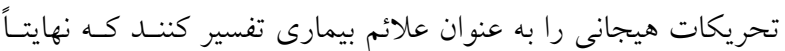

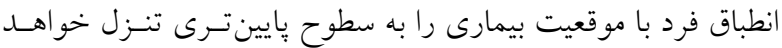

از ديكر يافتههاى يزوهش اين بود كه بيماران مبتلا بـه سـرطان،

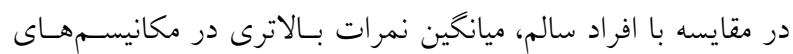

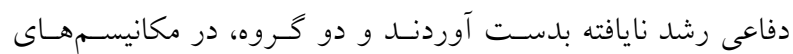

براى تعيين نقش متغيرهاى ييشبين (مكانيسمهاى دفاعى رشـــ يافته، رشد نايافته و نوروتيك) در تبيسين آلكسى تايميـا در بيمـاران

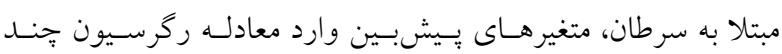

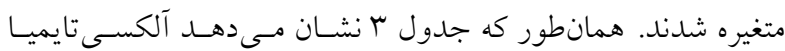

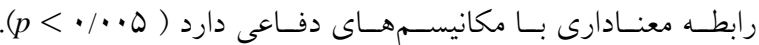
مكانيسمهاى دفاعى در مجموع ^ץ درصد از واريانس آلكسى تايميا

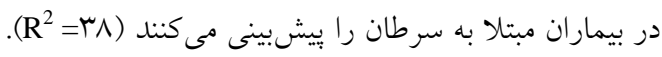

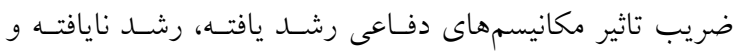

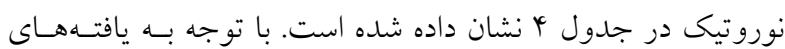
فوق مكانيسم دفاعى رشد نايافته قادر به ييشبينى آلكسى تايميا در

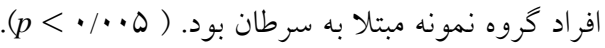

\section{بحث و نتيجه گيرى}

نتايج بدست آمده از اين بزروهش نشـان داد كـه در مقايسـه بـا

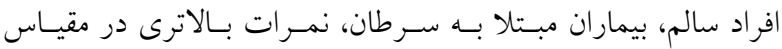
آلكسى تايميا و زيرمقياس دشـوارى در شناسـيى هيجانـات بدسـت

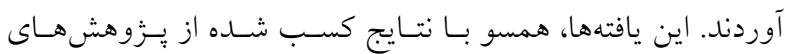

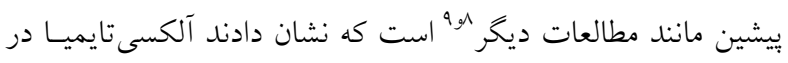

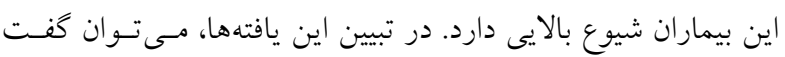


هيجانى مرتبط است كه با اطلاعات حساس و متناقض دريافتشـده از محيط مقابله و مانع از ادراك كامل و بهينه اين اطلاعات مى بوند. مكانيسم بازدارى هيجانى، كرايش به مسدود كـردن اطلاعـاتى دارد

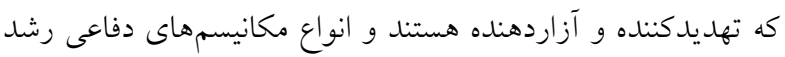
نايافته، وظيفه يكيار جِهردن و هماهنخساختن سيستم شناختى فـرد

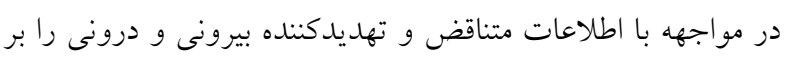
عهله دارد. بَ نتيجه فعالشدن مكانيسمهاى دفـاعى رشـــ نايافتـه در بيماران مبتلا به سرطان در نهايت افزايش بازدارى هيجانى، آلكسى تايميا و دشوارى در ادراى و تنظيم هيجانات منفى ناشى از شـرايط بيمارى است.

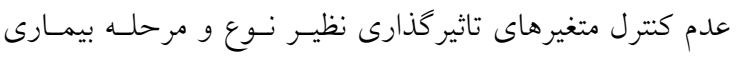
سرطان، نوع درمان انتخاب شده و جنسيت بيماران، ماهيت مقطعى لحسي

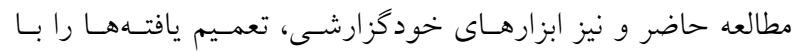

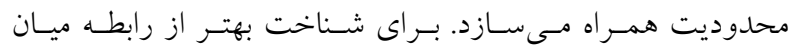

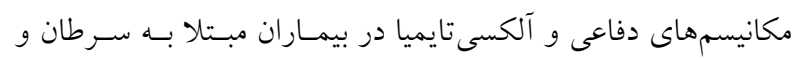

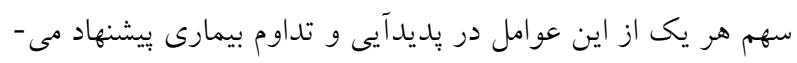
شود تا يزؤهش هاى بيشترى در مراحل مختلف بيمـارى و درمـان و نيز نوع سرطان صورت بحيرد. همجنين يزوهشهاى بيشتر به منظور

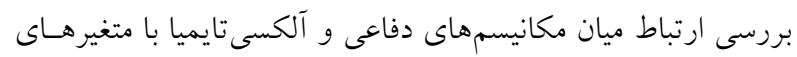

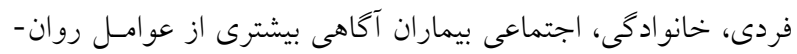

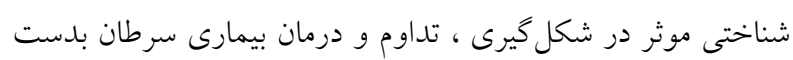
خواهد داد. بطور كلى، نتايج يزوهش حاضر نشان داد كه ميزان آلكسىتايميا در بيماران مبتلا به سرطان نسبت به افراد غيربـالينى و سـالم بـالاتر

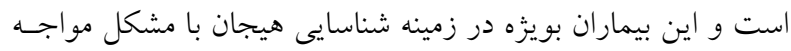

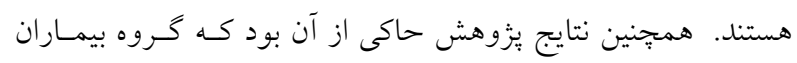

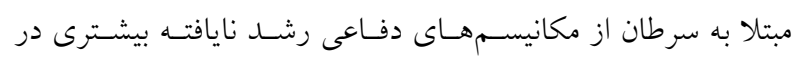
مقايسه با افراد سالم استفاده مى كردند. بعلاوه مكانيسمهـاى دفـاعى رشد نايافته، بيشبين مناسبى براى آلكسىى تايميـا در خـروه بيمـاران مبتلا به سرطان بود. بر اساس يافتهاى اين يزوهش مىتسوان نتيجـهـ

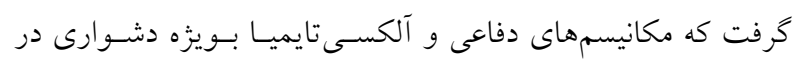
شناسايى هيجان از عوامل روانشناختى عمدهاى هستند كه در تجربه

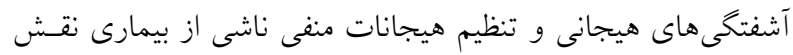
دارند. به دليل تاثيرات بالقوه مولفههاى روانشناختى تعيسين كنتـدهاى
دفاعى رشد يافته و نوروتيك با يكديخر تفاوتى نداشتند. همسـو بـاــا

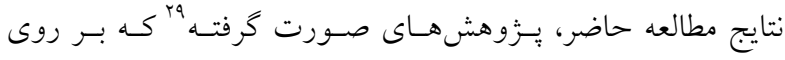
بيماران مبتلا به سرطان سـينه انجـام شـده نشـان داده كـه ميـانخين نمرات مكانيسمهاى دفاعى رشد نايافته و نوروتيك در اين بيمـاران، بالاتر از جمعيت غيربالينى است. بطور كلى، نتايج اغلـب مطالعـات

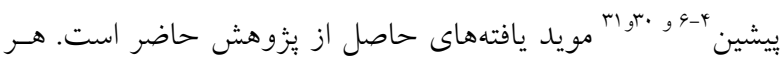

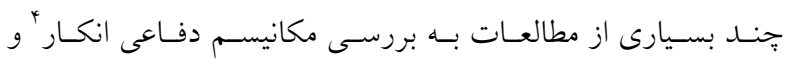

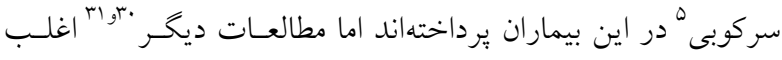
حاكى از استفاده بالاى اين بيماران از ساير مكانيسمهاى دفاعى رشد

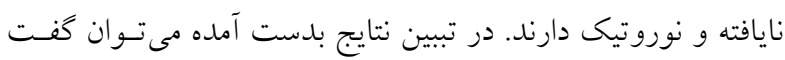

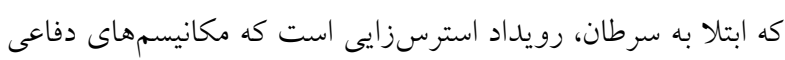
غالب فرد را راهاندازى كرده و منجر به ارائه بِاسخهاى روانشناختى

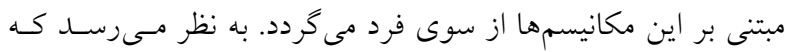

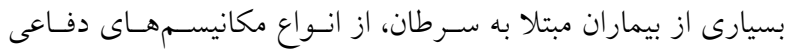

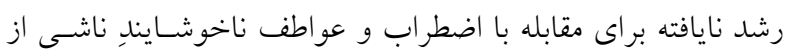
رويداد بيمارى استفاده مى كنند.

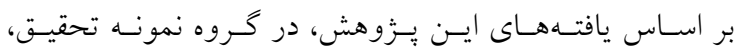
مكانيسم دفاعى رشد نايافته، يُشبين مناسبى براى آلكسى تايميا بود.

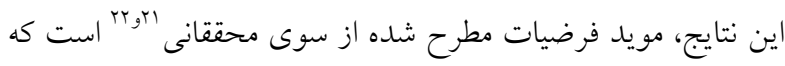
معتقدند مكانيسمهاى دفاعى رشد نايافته مانند انكار، منجر به ظهـور

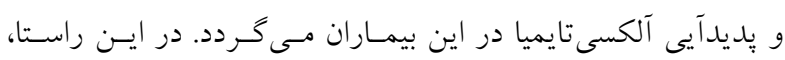

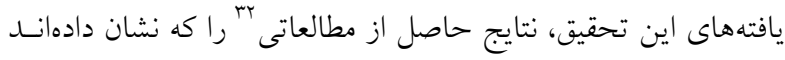

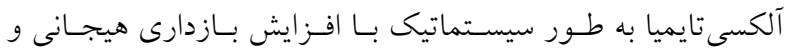
مكانيسمهاى دفاعى رشد نايافته ارتباط دارد تاييد مى كنـد. در تبيسين

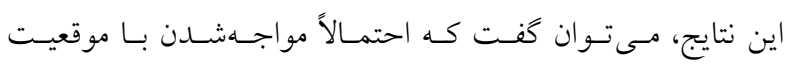

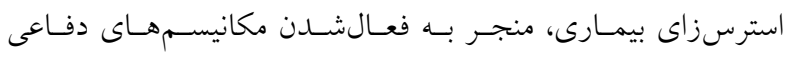

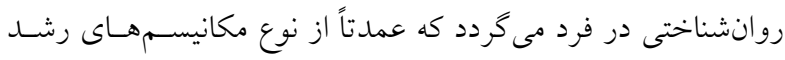
نايافته از قبيل انكار و سركوبى هستند. فعالشدن اين مكانيسمهـا در فرايند يردازش شناختى هيجانات اختلال ايجاد مى كنند. در نهايـت،

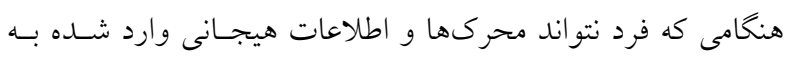

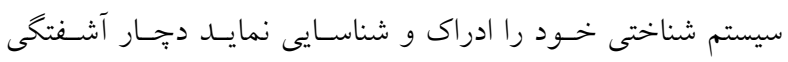
هيجانى مى گردد. اين آشفتكى هاى هيجانى به صورت آلكسى تايميـا

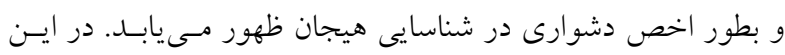
راستا، آلكسى تايميا غالبا با راهبردهاى ذهنى متعدد از قبيل بـازدارى 


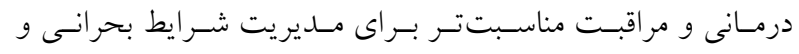

استرسزاى بيمارى سود ببرند. بررسى متغيرهاى روانشناختى نظيـر

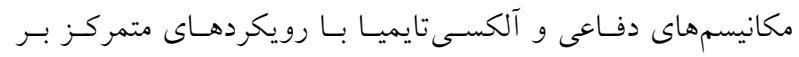

سببشناسى و جّكونكى تداوم و نحوه كاركرد آن در بيمـاران مبـتلا

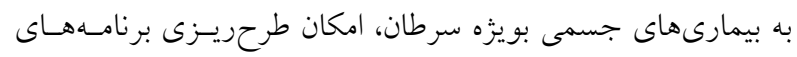

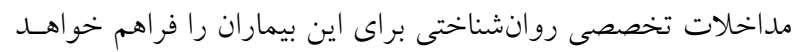

ساخت.

\section{References}

1. Prieto JM, Atala J, Blanch J, Carreras E, Rovira M, Cirera E, Espinal A, Gasto C. Role of depression as a predictor of mortality among cancer patients after stem-cell transplantation. J Clin Oncol. 2005; 23(25):6063-71.

2. Chida Y, Hamer M, Wardle J, Steptoe A. Do stressrelated psychosocial factors contribute to cancer incidence and survival? Nat Clin Pract Oncol. 2008; 5(8):466-75.

3. Vaillant, GE. Ego mechanisms of defense and personality psychopathology. J Abnorm Psychol. 1994; 103(20): 4450.

4. Wool MS. Extreme denial in breast cancer patients and capacity for object relations. Psychother Psychosom. 1986; 46: 196-204.

5. Hyphantis T, Paika V, Almyroudi A, Kampletsas EO, Pavlidis N. Personality variables as predictors of colorectal cancer patients' psychological distress and health related quality of life: a one-year prospective study. J Psychosom Res 2011; 70: 411-421.

6. Dumitrascu O, Jian E, Nicolae R, Horvat T. The psychological impact of lung Cancer Diagnosis. Proc. Rom. Acad. 2015; 1: 83-85.

7. Beresford TP, Alfers J, Mangum L, Clapp L, Martin B. Cancer survival probability as a function of ego defense (adaptive) mechanisms versus depressive symptoms. Psychosomatics. 2006; 47: 247-253.

8. Gritti, P; Lombardi, S; Nobile, B; Trappoliere, P; Gambardella, A; Di Caprio, EL; Resicato, G. Alexithymia and cancer-related fatigue: a controlled cross-sectional study. Tumor. 2010; 96(1):131-137.

9. Grassi L, Sabato S, Rossi E, Biancospino B, Marmai L. Use of the diagnostic criteria for psychosomatic research in oncology. Psychother Psychosom 2005; 74: 100-107.

10. Nemiah JC, Freyberger H, Sifneos PE: Alexithymia a view of the psychosomatic process. In: Hill OW (ed):

$$
\begin{aligned}
& \text { نظير مكانيسم دفاعى و آلكسىتايميا در ايجـاد، توسـعه و بيشـرفت }
\end{aligned}
$$

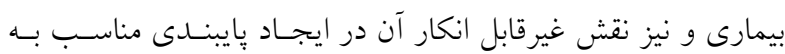

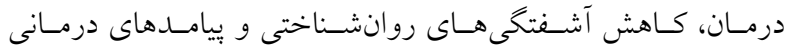

$$
\begin{aligned}
& \text { مطلوب، يزوهشهاى بيشتر در اين حوزه از اهميـت قابـل تـوجهى } \\
& \text { برخوردار مىشوند. شناخت مكانيسمهاى دفـاعى مـورد اسـتفاده در }
\end{aligned}
$$

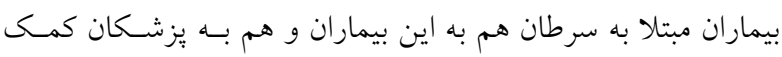

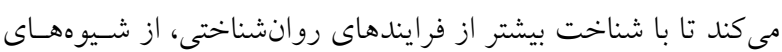

Modem Trends in Psychosomatic Medicine. London, Butterworths, 1976. pp 430-439.

11. Apfel RJ, Sifneos PE. Alexithymia: concept and measurement. Psychother Psychosom. 1979; 32:180-190.

12. Taylor GJ, Parker JD, Bagby RM. A preliminary investigation of alexithymia in men with psychoactive substance dependence. Am J Psychiatry 1990; 147: 12281230.

13. De Vries A.M.M. Forni V. Voellinger R. Stiefel F. Alexithymia in Cancer Patients: Review of the Literature. Psychother Psychosom. 2012; 81:79-86.

14. Porcelli P, Bagby RM, Taylor GJ, de Carne M, Leandro G, Todarello O: Alexithymia as predictor of treatment outcome in patients with functional gastrointestinal disorders. Psychosom Med. 2003; 65: 911-918.

15. Porcelli P, Tulipani C, Maiello E, Cilenti G, Todarello O: Alexithymia, coping, and illness behavior correlates of pain experience in cancer patients. Psychooncology 2007; 16: 644-650.

16. Manna G, Foddai E, Di Maggio MG, Pace F, Colucci G, Gebbia N, Russo A: Emotional expression and coping style in female breast cancer. Ann Oncol. 2007; 18:vi77vi80.

17. Ripetti V, Ausania F, Bruni R, Campoli G, and Coppola R. Quality of life following colorectal cancer surgery: the role of alexithymia. Eur Surg Res. 2008; 41: 324-330.

18. Luminet O, Rokbani L, Ogez D, Jadoulle V: An evaluation of the absolute and relative stability of alexithymia in women with breast cancer. J Psychosom Res. 2007; 62: 641-648.

19. Grassi L, Rossi E, Sabato S, Cruciani G, Zambelli M: Diagnostic criteria for psychosomatic research and psychosocial variables in breast cancer patients. Psychosomatics 2004; 45: 483-491. 
20. De Gucht V, Fontaine J, Fischler B. Temporal stability and differential relationships with neuroticism and extraversion of the three subscales of the 20-Item Toronto Alexithymia Scale in clinical and nonclinical samples. J Psychosom Res. 2004; 37:25-33.

21. Martínez-Sánchez F, Ato-García M, Ortiz-Soria B. Alexithymia State or trait? Span J Psychology 2003; 6:51-9.

22. Freyberger H. Supportive psychotherapeutic techniques in primary and secondary alexithymia. Psychother Psychosom. 1977; 28: 337-342.

23. Bonanno GA, Singer JL. Repressive personality style: theoretical and methodological implications for health and pathology. In: Singer JL (ed): Repression and Dissociation: Implications for Personality Theory, Psychopathology and Health. Chicago, IL: University of Chicago Press, 1990:435- 470.

24. De Vries A.M.M. Forni V. Voellinger R. Stiefel F. Alexithymia in Cancer Patients: Review of the Literature. Psychother Psychosom 2012; 81:79-86.

25. Andrews G, Singh M, Bond M. The Defense Style Questionnaire. J Nerv Ment Dis. 1993; 181 (1): 246-256.

26. Besharat MA, Irawani M, Sharifi M. An investigation relationship between attachment style and defense mechanisms. Journal of psychology 2001; 3(19): 277289 .

27. Besharat MA. Reliability and factorial validity of a Farsi version of the 20-item Toronto Alexithymia Scale with a sample of Iranian students. Psychol Rep. 2007; 101(1):209-220.

28. Katz J, Martin AL, Pag_e MG, Calleri V: Alexithymia and fear of pain independently predict heat pain intensity ratings among undergraduate university students. Pain Res Manag. 2009; 14:299-305.

29. Khodamoradi S, Besharat MA, Hemmati A. The comparison of defense mechanisms in patients suffering from breast cancer with those of nonclinical group. Yafteh 2013; 15(3): 76-86.[In Persian]

30. Zachariae R, Jensen AB, Pedersen C, et al. Repressive coping before and after diagnosis of breast cancer. Psycho-Oncology 2004; 13: 547-561.

31. Perri JC, Metzger J, Sigal JJ. Defensive functioning among women with breast cancer and Matched Community Controls. Psychiatry 2015; 78(2): 156-169.

32. Helmes E, McNeill P, Holden RR, Jackson C. The construct of alexithymia: association with defense mechanisms. J Clin Psychol. 2008; 64(3): 332-337. 